\title{
Investment Risk Management under Conditions of Digitalization
}

\author{
Elena Letiagina ${ }^{1, *}$, and Dmitry Malov $^{2}$ \\ ${ }^{1}$ Lobachevsky State University of Nizhni Novgorod, 603095 Nizhny Novgorod, Russia \\ ${ }^{2}$ Alfa bank, Derivatives Department, 107078 Moscow, Russia
}

\begin{abstract}
Under conditions of evolving digital economy, in view of speedy progress of science and technology, the need to take investment decisions and analyze vast data flows, it is very important to introduce new effective approaches to risk management. The authors integrate the scientists' modern views in the risk management area. The article discusses specific features of risk management in the process of attracting investment in digitalization projects. This study contributes to understanding investment risks and helps determine directions of future strategies aimed at developing investment activities within the framework of digital economy. The work results can be used in developing a risk management system and forming a digital investment portfolio. The analysis of risk management approaches and techniques conducted helped provide a practical and expedient scientific basis for further development of digital ecosystems.
\end{abstract}

\section{Introduction}

Investment projects are implemented under the impact of risk and uncertainty factors typical of Industry 4.0, and it is not easy to predict their deliverables [1, 2, 3]. Digitalization leads to existing business models changed and production processes upgraded, thus modifying the system of risks arising from the inability to assess the prospects of the market situation [4-7].

The concept of risk in economy has emerged relatively recently. Previously, his assessment was used in engineering, when complex equipment was designed. Meanwhile, risk assessment methods were unreliable in organizational and economic systems. The concept of risk management was based on the hypothesis of production process determinism: it was assumed that there was an impact to bring an object to a given state, and management was to assess this impact.

In the scientific literature, there are various approaches in scientific literature to defining the investment risk. In general, risk is understood as a measure of uncertainty of cash flows from capital investments, on the one hand, and of the instability of cash flows from investments over the life of the project, on the other hand.

\footnotetext{
* Corresponding author: helenlet @yandex.ru
} 
The research work of many scientists is devoted to studying industry-specific features of investment risk management. Megits et al. [8] identified the causes and characteristics of investment risks in the base material sector using the example of the gold mining market, studied the investment risk components, analyzed the principal techniques of insuring them, and conducted a conceptual analysis of the investment risk in this industry. Botín, Guzmán and Smith [9] proposed an approach based on assessing the investment risk at every stage in the life cycle of a mining project, from exploration to mine closure, while risk management is carried out as part of a phased process of value added optimization.

Li developed an integrated approach to determining the investment risk in construction business [10]. The author identified the key factors affecting its value, including economic, technological, market, managerial and political ones.

To effectively assess the investment risk in energy business, Duan et al. roposed a new system of indicators, including resource potential, investment environment, national economy development factors, environmental restrictions, and political risks [11].

Kul, Zhang and Solangi proposed a three-step decision-making system for assessing and studying risk factors [12]. The first step is identifying risk factors using the Delphi method. The second step is assessing the identified risk factors by using the Analytical Hierarchy Process (AHP). The third step is to assess and prioritize risk mitigation strategies by using Fuzzy Weighted Aggregated Sum Product Assessment (FWASPAS).

Domnikov et al. [13] developed an algorithm of taking an investment decision in oil and gas industry requiring significant initial investments based on the two-criterion performance indicator with due regard for investment risks and comparing target vs. low solubility.

Chen and $\mathrm{Hu}$ proposed the analysis indicator system for chemical industry, which includes four factors: profitability, operation capacity, solvency, and development capacity [14].

An integrated approach to the assessment and analysis of investment risks was developed by Garnova, Zvyagin and Sviridova. Risk assessment is carried out by using fuzzy logic and V\&M methods, which form a full range of investment scenarios and determine unacceptable risk values [15].

Despite a large amount of research in the risk management area and increased access to digital sources of information and knowledge, risk, uncertainty, instability, complexity and ambiguity continue to reduce the effectiveness of management decisions made in the area of investing in digitalization projects.

\section{Methods and materials}

Under present-day conditions of digital economy, the attention of scientific community is focused on studying topical issues of risk management in digitalization projects. Theoretical methods were used, including description, analysis and synthesis, the additive method, functional analysis method, and scenario method.

The investment risk in digital economy is taken to mean a measure of uncertainty and assumes to use the probability of the target level of the rate of return. Risk accounting in this case is carried out by adjusting the cash flows under the digitalization project $\left(Y_{t j}\right)$, when the average expected value is used instead of the values of the flow expected in certain periods of time. It is calculated as the weighted average of income $Y_{t j}$ expected for the corresponding period of time for various project scenarios (determined as $j=1, \ldots, m$ ), taking into account the weights $\left(p_{i t}\right)$ in the form of the probability of this income or scenario:

$$
Y_{t}=Y_{1} * p_{1 t}+Y_{2} * p_{2 t}+\cdots Y_{m} * p_{m t}
$$


Using the investment risk as a measure of instability of cash flows in the process of implementing a digitalization project assumes that the main indicator of risk is the standard deviation $(\sigma)$ of income from a digital project in future periods of time from the average annual income of an investor for the digitalization project cycle after investments.

The standard deviation is often calculated not for indicators of absolute income (Y), but of profitability (y) on ruble of capital investment:

$$
\sigma=\sqrt{\sum_{t=1}^{n}\left(y_{t}-\bar{y}\right)^{2} / n}
$$

where: $t=1 \ldots n$ are numbers of digitalization project cycle periods; $y_{t}$ is income on 1 ruble of investment within the period $t ; \bar{y}$ is average income on 1 dollar during one project period.

In practical terms, the problem of measuring the project risk is solved in relation to a specific tool. It should be emphasized that if the variability of project profit margin does not change over time, then the standard deviation of income on $\$ 1$ of investment is taken as the standard deviation observed in the past. However, the level of risk in the past is assumed to be the level of risk in future.

Such an approach to assessing the investment risk is advisable if the main factors of the investment risk remain unchanged. This is typical for investing in stocks of enterprises whose profitability fluctuation can be explained by the systematic risks of the enterprise brought about by their industry affiliation in a stable economy and a mature state of the money market with its own digital development strategy.

\section{Results and discussions}

Research conducted by Sadeh and Dvir demonstrated no contradiction between high levels of the risk or uncertainty and business success[16].

Among the concepts of risk analysis, two approaches can be especially distinguished [17]:

- a risk is determined by aggregation of damage with due regard for its probability;

- a risk is determined by the aggregation of risks arising a decision and external risks;

- These approaches fail to take into account:

- difference between "risk" and "uncertainty" notions;

- risk subjectivity;

- that the risk assessment criteria range is usually reduced to a single indicator.

Based on the nature of a risk, there are two approaches to risk management in digital economy:

1. Forecasting digitalization crises and taking steps to eliminate them;

2. Developing alternative sources to mitigate damages caused by a crisis.

The first approach is theoretical, since an accurate forecast of digital development and elimination of crises is difficult to implement in practice.

The second approach includes three areas of risk management:

- insurance;

- accumulating reserve funds or self-insurance;

- diversifying risks.

One of the ways to mitigate digitalization risks of is to transfer them to the insurer, who will accept them for a fee and pay compensation when an insured event occurs.

The risk management mechanism by creating reserve funds is similar to the insurance mechanism, except that the funds are accumulated at the enterprise itself (self-insurance). 
The third approach is used if there are several areas of investments (digital investment portfolio).

The goals of the digital investment portfolio include:

- maximizing its profitability at an acceptable risk level;

- mitigating the investment risk at the sufficient profitability level.

Both goals are achieved through diversification: its essence is that there are digital projects with multidirectional profit margins in a digital investment portfolio, but with the same change in external conditions. The more digital projects in the portfolio, the less a risk. Moreover, it is decreased not linearly, but hyperbolically, since each new project in the portfolio reduces portfolio risk by an ever smaller amount (Fig. 1).

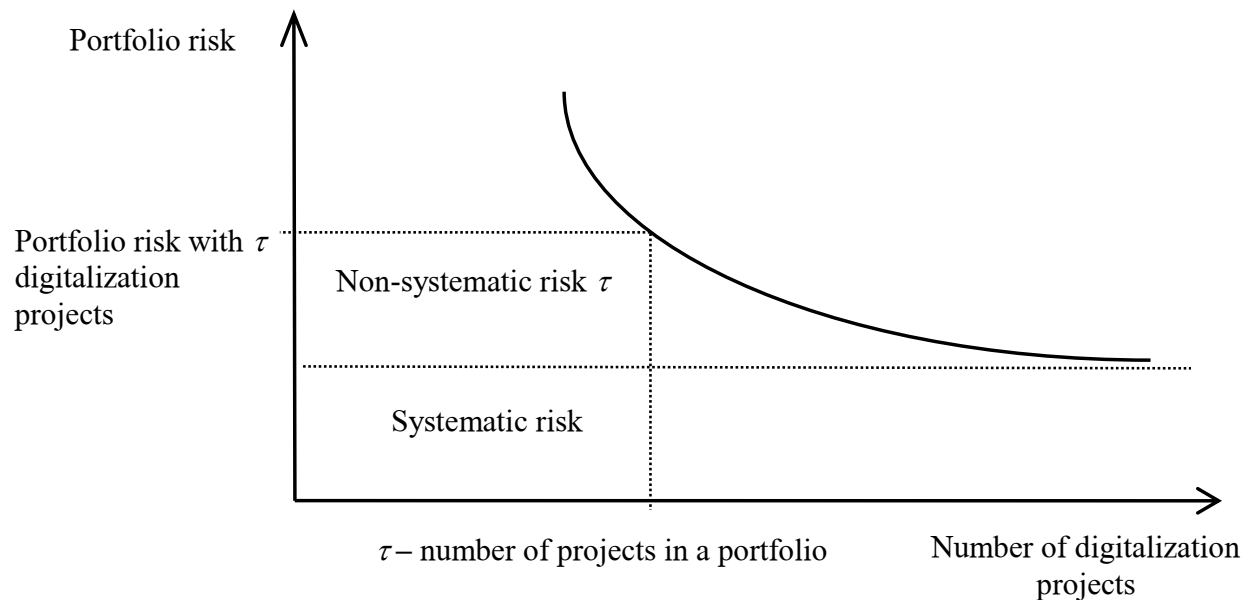

Fig. 1. Portfolio risk vs. the number of digital projects in a portfolio

Figure 1 clearly shows that with an increase in the number of digital projects, portfolio risk decreases hyperbolically, which tends to a straight line parallel to the abscissa axis, reflecting the level of the market risk. Thus, the risk for $\tau$ projects consists of specific risk $\tau$ and the market risk for portfolio digital projects $(\tau)$.

If the number $(\tau)$ grows, then the portfolio risk decreases only by mitigating a specific risk, and the market risk remains constant, all other conditions being equal. With an increase in the number $(\tau)$, the specific risk decreases, but not to zero for any, arbitrarily large value of $\tau$.

This relation is considered for a specific moment in time and is static, $t=$ const. If this condition is violated, many parameters may change over time, and the curve may shift relative to the $\mathrm{X}$ axis and change the degree of its steepness, but it will still remain a hyperbole.

\section{Conclusions}

1. The authors systematize the modern scientific views in the area of risk management and investment risks.

2. The economic efficiency of large enterprises and holdings is much higher than that of medium and small enterprises. Corporations generally tend to adopt more sophisticated and innovative initiatives than start-up firms. The authors substantiate the technology risk importance in relation to market uncertainty. And while the risk can negatively impact a company's profitability, it is also a source of new opportunities in the digital environment. 
3. The more digital projects in the investment portfolio, the less a risk. Thus, with an increase in the number of digital projects in the portfolio, the risk decreases only due to non-systematic risks.

4. The concept of risk and profitability makes it possible to develop tools for managing cash flows in investment design in the process of digitalizing enterprise activities.

\section{References}

1. Y.S. Potashnik, M.V. Artemyeva, S.N. Kuznetsova, A.P. Garin, E.N. Letyagina, Lect. Notes. Netw. Syst., 73, 525 (2020)

2. E.N. Letiagina, Y.V. Trifonov, E.Y. Trifonova, A.N. Vizgunov, J.A. Grinevich, Lect. Notes. Netw. Syst., 91, 134 (2020)

3. N.N. Kiseleva, N.R. Gukasova, A.A. Tikhomirov, E.V. Lyapuntsova, S.A.Sklyarenko, Res. J. Pharm. Sci., 7(1), 2214 (2016)

4. J. Jin, L. Ma, X. Ye, Asian. J. Technol. Inno., 1, 28 (2020)

5. M. Rachinger, R. Rauter, C. Mueller, Christiana, J. Manuf. Technol. Manag., 30(8), 1143 (2019)

6. W. Baber, A. Ojala, R. Martinez, J. Small Bus., 26, 6/7 (2019)

7. A. Caliskan, O. Ozen, D. Yesim, Y. Ozturkoglu, J. Inf. Manag., (2020)

8. N. Megits, S. Reverchuk, L. Chyzh, J. East. Eur., 1(1), 8, (2014)

9. J.A. Botín, R.R. Guzmán, M.L. Smith, DYNA, 78(170), 221 (2011)

10. X.-J. Li, J. Civ. Eng. Manag., 26(7), 599 (2020)

11. F. Duan, Q. Ji, B.-Y. Liu, Y. Fan, J. Clean. Prod., 170, 535 (2018)

12. C. Kul, L. Zhang, Y.A. Solangi, J. Clean. Prod., 276, 124 (2020)

13. A. Domnikov, G. Chebotareva, P. Khomenko, M. Khodorovsky, Int. J. Sust. Dev. World. Plan., 12(5), 946 (2017)

14. L. Chen, L. Hu, Chem. Engineer. Trans., 71, 175 (2018)

15. E. Garnova, L. Zvyagin, O. Sviridova, Int. J. Econ. Bus., 7, 447 (2019)

16. A. Sadeh, D.O.V. Dvir, Int. J. Innovat. Manag., 24, 5 (2020)

17. Osnovy investirovanija $=$ Fundamentals of investing, Lorens Dzh. Gitman, Majkl D. Dzhonk, Moskva, 991 (1999) 